\title{
Echocardiographic abnormalities in non-moderate drinking of alcohol for prolonged duration
}

\author{
M.P. Gautam ${ }^{1}$, U. Ghimire Gautam ${ }^{2}$, S. Dwivedi ${ }^{3}$, S. Rijal ${ }^{4}$ \\ ${ }^{1}$ DM Cardiology student, College of Medical Sciences, Bharatpur, Nepal, ${ }^{2}$ Facilitator, NAPA, Ministry of Environment, \\ Government of Nepal, ${ }^{3}$ Professor, Department of Medicine, University College of Medical Sciences, New Delhi, India \\ ${ }^{4}$ Professor, Department of Medicine, B P Koirala Institute of Health Sciences, Dharan, Nepal
}

\begin{abstract}
Background: Alcohol drinking is cardio-protective; however its beneficial and harmful effects depend on the amount consumed. This work is designed to assess the impact of prolonged non-moderate drinking in left ventricular mass index and left ventricular ejection fraction and the correlation of their severity with total lifetime intake amount.

Materials and methods: Fifty non-moderate drinkers (>25 g/day) for last 10 years and 50 non-drinkervolunteers were selected. Detail echocardiographic assessment was done and findings were compared and severity was correlated with lifetime amount.
\end{abstract}

Results: Mean daily intake, duration and lifetime intake amount of alcohol were $64.1 \mathrm{~g}, 21.9$ years and $501.9 \mathrm{Kg}$ respectively. The mean ejection fraction and left ventricular mass index were $47.2 \%$ and 105.3 $\mathrm{g} / \mathrm{m}^{2}$. There was significant difference when compared with controls. Eighty-two percent drinking subjects had abnormal echo, most common were regurgitations (52\%), diastolic dysfunction (46\%), raised ventricular mass (44\%), systolic dysfunction (40\%), and dilated left atrium and ventricle (38\%). Thirtyfour percent of subjects had echo features consistent with dilated cardiomyopathy. Palpitation and dyspnea in combination were the only symptoms associated with severity of echo changes. There was strong negative correlation of lifetime intake amount with ejection fraction ( $r=-0.91, p<0.001)$; however its relationship with ventricular mass index was not statistically significant $(r=0.23, p>0.05)$.

Conclusions: Prolonged non-moderate drinking causes significant echocardiographic abnormalities mainly systolic dysfunction and increased left ventricular mass index. The total lifetime and daily amount of alcohol are well correlated with systolic dysfunction; however their relationships with the left ventricular mass index were non-conclusive.

Kew words : Alcohol, left ventricular mass, cardiomyopathy

Correspondence: Dr. M.P. Gautam

E-mail:manipdgautam@yahoo.com,manigautam@gmail.com 
MP Gautam et al. Echocardiographic abnormalities in non-moderate drinking of alcohol for prolonged duration

\section{Introduction}

The putative cardioprotective effect of alcohol has narrow range. Moderate drinking of alcohol has beneficial effects on cardiovascular health. However, the same is not the rule in case of non-moderate drinking. Consumption of 1 or 2 drinks per day is associated with a reduction in risk of dying from coronary heart disease by approximately $30-50 \% .^{1-3}$ The overall effects of alcohol consumption on cardiovascular healthdepend on the amount of alcohol consumed and the duration of intake. It has been clearly demonstrated that there is a $\mathrm{J}$ or $\mathrm{U}$ shaped relation between alcohol consumption and total mortality. ${ }^{2,3}$ The lowest mortality occurs in those who consume 12 $-24 \mathrm{~g}$ of ethanol per day. Non-moderate drinking is associated with congestive heart failure, hypertension, arrhythmias and sudden cardiac death, ${ }^{4-7}$ and it is the major identifiable cause of secondary dilated cardiomyopathy (DCM) which is responsible for one third of all cases. ${ }^{8-10}$

Prolonged excessive drinking causes various structural and functional abnormalities of heart which can be detected on echocardiography (Echo) and reversibility of these changes has also been recorded in those who have abstained. Long-term alcoholism is associated with symptomatic left ventricular dysfunction in one third of cases, ${ }^{11}$ whereas two thirds of them without symptoms demonstrate significant cardiac abnormalities on echocardiography. ${ }^{12}$ In addition, the symptoms of heart failure in these patients do not differ to that from other causes; however few studies had reported poorer prognosis in subjects with alcoholic cardiomyopathy when compared with patients with idiopathic DCM. ${ }^{13}$ But, it is not clear, whether this is due to a more severe form of disease or difficulties to abstain from alcohol and follow medical prescriptions. Abstinence after mild impairment in cardiac function and increased left ventricular mass (LVM) can stop progression or even reverse symptoms in some cases with improvement in ventricular function, otherwise severe heart failure ensues leading to a poor prognosis. ${ }^{14,15}$ Although, the abstinence does not guarantee a clinical improvement in all subjects and myocardial damage may continue to progress, it is the only available effective and economic way to prevent the deterioration. In addition, it has also been observed that the abstinence is effective only in early stage; otherwise, repetitive non-moderate drinking is very harmful and causes worsening. ${ }^{16}$

Echocardiography can be an effective tool in screening of asymptomatic alcohol users who might be at risk for various cardiovascular diseases. This study aims to evaluate the echocardiographically detected structural and functional myocardial changes: particularly LVM and left ventricular (LV) systolic function in these alcoholic subjects and compare these findings with that of healthy controls. It also aims to clarify the dose dependant severity of these cardiac changes.

\section{Materials and methods}

This study was conducted during 2002 - 2003 at B P Koirala Institute of Health Sciences, a tertiary referral center in eastern region of Nepal, after getting an approval from the ethical committee. It included two groups: alcohol users and alcohol free subjects of 30 - 55 years age. Alcohol users were subjects with non-moderate drinking; i.e. at risk drinking (National Institute on Alcoholism and Alcohol Abuses) ${ }^{17,18}(>2$ standard drinks or $\geq 25 \mathrm{~g} /$ day of ethanol equivalent to $250 \mathrm{ml}$ of homemade liquor or $230 \mathrm{ml}$ of non- fortified wine, $86 \mathrm{ml}$ of whisky or vodka) for at least 10 years 
or more. Alcohol free subjects were taken as control group. Subjects suffering from coronary artery disease, diabetes, thyroid disorders, chronic obstructive airway disease and cor pulmonale, rheumatic heart disease, connective tissue disorders, advance hepatic or renal disease were excluded. Subjects with known hypertension and females in peripartum period were also excluded.

A detailed history of drinking including types, frequency and average amount were recorded. The current daily intake was considered to be the average of alcohol consumed per day during the last month. Life events such as marriage, military service, festivals and work posts were used as "anchor points" to assist in recollection (time-line follow-back method). ${ }^{19}$ Comprehensive clinical assessment was carried out using structured protocol after an informed consent. Each subject underwent detail echocardiographic assessment.

The strength of different alcoholic beverages was taken as: ${ }^{19}$ beers $3.4-9 \% \mathrm{v} / \mathrm{v}$, white wine $8-13 \% \mathrm{v} / \mathrm{v}$, vodka $37.5-57.5 \% \mathrm{v} / \mathrm{v}$, whisky $32-40 \% \mathrm{v} / \mathrm{v}$, rum $32-40 \% \mathrm{v} / \mathrm{v}$.

\section{Echocardiographic study:}

M-mode measurements were made according to American Society of Echocardiography (ASE) criterion. ${ }^{20}$ Observed LVM was calculated from the formula described by Devereux and associates using echocardiographic parameters. ${ }^{21,22}$

LVM $($ grams $)=0.80 \times 1.04\left[(\text { IVSd }+ \text { LVIDd }+ \text { LVPWd })^{3}-(\right.$ LVIDd $)$ $\left.{ }^{3}\right]+0.6$

Where IVSd, LVIDd and LVPWd denote interventricular septal thickness, LV internal dimension and LV posterior wall thickness at end diastole respectively. The expected LVM (grams) was calculated by using the equations: ${ }^{22}$
LVM for Men = $16.6[\text { Weight }(\mathrm{Kg})]^{0.51}$ and for Women $=13.9$ [Weight $(\mathrm{Kg})]^{0.51}$.

If the ratio, observed/expected LVM was 0.69 to 1.47 , observed LVM was considered as normal and if it was $>1.47$, observed LVM was considered increased. ${ }^{22} \mathrm{M}$-mode measurements were used for assessing the left ventricular ejection fraction (LVEF). LV regional wall motion abnormality was subjectively assessed in the parasternal short-axis, apical fourchamber, and apical two-chamberviews, using the 20segment model proposed by the ASE. ${ }^{23}$ Diastolic dysfunction was defined as $\mathrm{E} / \mathrm{A}$ ratio equal or less than 1, dilated left atrium (LA) and LV were defined as index more than $2.2 \mathrm{~cm} / \mathrm{m}^{2}$ and $3.2 \mathrm{~cm} / \mathrm{m}^{2}$ respectively. ${ }^{24}$

Subject was labeled as having DCM in the presence of $\mathrm{LVEF}<45 \%$ and dilated LV i.e. LVIDd/ BSA $>3.2 \mathrm{~cm} / \mathrm{m}^{2} .{ }^{25}$ If there was only one of them, possible DCM was diagnosed. ${ }^{26}$ The LVEF was classified as - normal (>51\%), borderline (46-50\%), impaired (mild-41-45\%, moderate-31-40\% and severe $(30 \%)$.

\section{Statistical analysis}

SPSS was used for data processing and analysis. The mean and standard deviation of different variables were calculated and compared between alcoholic and non-alcoholic subjects. The correlations of LVM index and LVEF with the total lifetime and daily intake amount and duration were assessed by calculating Pearson's coefficient.

The significance of any differences in means between alcohol users and healthy control group was tested using $\mathrm{F}$ test and between the groups with different amount was tested using student's t test. The significance of correlation analysis was determined by 
MP Gautam et al. Echocardiographic abnormalities in non-moderate drinking of alcohol for prolonged duration

locating corresponding $\mathrm{p}$ value from table. The confidence intervals were calculated at the $95 \%$ level. $\mathrm{P}$ values $<0.05$ were considered statistically significant at $5 \%$ level and $<0.01$ at $1 \%$ level.

\section{Results}

The baseline characteristics of the subjects and controls were comparable except for smoking, which was more prevalent among alcohol users (Table I).

Table I. Baseline characteristics.

\begin{tabular}{llll}
\hline Characteristic & $\begin{array}{l}\text { Alcohol user } \\
(n=50)\end{array}$ & $\begin{array}{l}\text { Control } \\
(n=50)\end{array}$ & \begin{tabular}{l}
$P$ value \\
\hline M:F
\end{tabular} \\
\hline Mean age (yrs) & $45.13: 1$ & $1.08: 1$ & 0.15 \\
Mean BMI $\left(\mathrm{Kg} / \mathrm{m}^{2}\right)$ & 21.6 & 44.78 & 0.84 \\
Mean BSA $\left(\mathrm{m}^{2}\right)$ & 1.56 & 21.63 & 0.96 \\
Smoking $(\%)$ & $33(66)$ & 1.54 & 0.54 \\
Systolic BP & 117.5 & $21(42)$ & 0.02 \\
Diastolic BP & 76.52 & 118.6 & 0.13 \\
\hline
\end{tabular}

Among alcohol users, mean alcohol consumption was $64.3 \mathrm{~g} /$ day with a range of 25 to 150 gram and the mean duration was 21.9 year ranging from 10 to 40 year. Mean lifetime alcohol amount was $501.9 \mathrm{Kg}$ with a range of 91.2 to $1277.5 \mathrm{Kg}$. The lifetime intake of alcohol was less than $250 \mathrm{Kg}$ in $14 \%, 250-500 \mathrm{Kg}$ in $44 \%$ and more than $500 \mathrm{Kg}$ in $42 \%$ alcohol users.

There were statistically significant differences in the echocardiographic findings including $\mathrm{LV}$ dimensions (Table II) and calculated parameters between these two groups.
Table II. Mean Echo dimensions of alcohol users and controls.

\begin{tabular}{|c|c|c|c|}
\hline $\begin{array}{l}\text { Parameters } \\
(\mathrm{cm}) \\
\end{array}$ & $\begin{array}{l}\text { Alcohol users } \\
(n=50)\end{array}$ & $\begin{array}{l}\text { Control } \\
(n=50)\end{array}$ & $P$ value \\
\hline LVIDd & 4.84 & 4.32 & 0.0001 \\
\hline LVIDs & 3.54 & 2.69 & 0.0001 \\
\hline IVSd & 0.97 & 0.9 & 0.01 \\
\hline IVSs & 1.31 & 1.28 & 0.4 \\
\hline LVPWd & 0.95 & 0.85 & 0.001 \\
\hline LVPWs & 1.32 & 1.27 & 0.19 \\
\hline LA size & 3.33 & 2.51 & 0.0001 \\
\hline
\end{tabular}

The findings in alcohol free volunteers were comparable to standard normal values. The majority of the mean values of LV dimensions among alcohol users were also within the normal range, however, there was significant difference when compared to that of volunteers. There was a significant difference in left ventricular echo parameters between these two groups with a trend towards LV dilatation and diastolic thickening of interventricular septum and LV posterior wall in alcohol users. Regarding calculated parameters, alcohol users had significantly lower mean LVEF and higher LVM when compared with that of alcohol free subjects (Table III).

Table III. Calculated mean Echo parameters in alcohol users and controls.

\begin{tabular}{llll}
\hline Particulars & $\begin{array}{c}\text { Alcohol users } \\
(n=50)\end{array}$ & $\begin{array}{l}\text { Controls } \\
(n=50)\end{array}$ & P value \\
\hline LV Ejection Fraction $(\%)$ & 52.4 & 67.44 & 0.000001 \\
LV Mass $(\mathrm{g})$ & 164.3 & 121.69 & 0.000001 \\
LV Mass index $\left(\mathrm{g} / \mathrm{m}^{2}\right)$ & 105.3 & 75.87 & 0.000001 \\
Ratio of observed/ & & & \\
expected LVM & 1.35 & 1.03 & 0.000001 \\
\hline
\end{tabular}


Although the absolute mean values of LVEF and LVM index in alcohol users were within normal range, LVEF was impaired in $40 \%$ subjects (mild - 55\%, moderate $-40 \%$ and severe $-5 \%$ ), borderline in $8 \%$, and normal in $52 \%$ and LVM was raised in $44 \%$ subjects (Table IV).

Table IV. Echocardiographic abnormalities in alcohol users.

\begin{tabular}{l|l}
\hline Particulars & $\begin{array}{l}\text { Alcohol user } \\
(n=50)\end{array}$ \\
\hline Impaired LVEF & $20(40)$ \\
Increased in LVM & $22(44)$ \\
Diastolic dysfunction & $23(46)$ \\
Dilated LV & $19(38$ \\
Dilated LA & $19(38)$ \\
Regurgitations & $26(52)$ \\
MR & $12(24)$ \\
TR & $2(4)$ \\
MR and TR & $11(22)$ \\
\hline
\end{tabular}

Thirty-four percent of alcohol users had DCM and another $10 \%$ had possible DCM. In a sub-analysis, none of the subjects with total lifetime alcohol consumption less than $250 \mathrm{Kg}$ had developed impaired $\operatorname{LVEF}(<45 \%)$ and of those taking $250-500 \mathrm{Kg}$, only $13.64 \%$ had developed impaired LVEF, whereas $76.19 \%$ subjects taking more than $500 \mathrm{Kg}$ had developed LV systolic dysfunction. Diastolic dysfunction was seen in $46 \%$ of cases. Dilated LA and $\mathrm{LV}$ were observed in $38 \%$ cases. Regurgitations were observed in $52 \%$ cases [MR (24\%), MR \& TR (18\%)]. These values in alcohol free volunteers were within normal range except few of them had trivial TR $(8 \%)$.

Only $32 \%$ subjects were symptomatic and palpitation and dyspnea in combination were the only specific symptoms significantly associated with impaired LVEF ( $\mathrm{p}<0.05)$. Other symptoms were equally common in subjects with normal and impaired LVEF. More than $88 \%$ asymptomatic subjects had abnormal echocardiography including features of $\operatorname{DCM}(23.53 \%)$, possible DCM (14.71\%), diastolic dysfunction (52.94\%), dilated LV (29.41\%), dilated LA (35.29\%), impaired EF (32.35\%), increased LVM (64.71\%), isolated MR (17.65\%) and MR and TR (20.59\%). However, only the rate of DCM was more common in symptomatic subjects ( 56.25 vs $23.53 \%, \mathrm{p}<0.05)$ and others have similar incidence in both groups.

Among the subjects with DCM, more than $82 \%$ subjects were male and the mean age was 48.18 years with a range 38 to 55 year. Mean daily amount of alcohol intake was $91.18 \mathrm{~g}$ with a range of 40 to $150 \mathrm{~g} /$ day, mean duration was 26.64 year with a range of 13 to 39 years and total lifetime intake amount was $822.54 \mathrm{Kg}$ with a range of 547.5 to $1277.5 \mathrm{Kg}$. Nearly $90 \%$ of alcohol users with DCM had increased LVM(Table V).

Table V. Mean echo parameters and number of subjects with DCM.

\begin{tabular}{l|l}
\hline Characteristic & $D C M(n=17)$ \\
\hline LVEF (\%) & 39.24 \\
LV Mass (g) & 197.62 \\
Ratio of observed to expected & 1.63 \\
LVM & \\
LA size (cm) & 3.62 \\
LV size (cm) & 5.58 \\
\hline Increased LVM (percentage) & $15(88.24)$ \\
Diastolic dysfunction & $6(35.29)$ \\
LA dilated & $13(76.47)$ \\
Regurgitation & $17(100)$ \\
MR & $8(47.06)$ \\
TR & $1(5.88)$ \\
MR \& TR & $8(47.06)$ \\
\hline
\end{tabular}


MP Gautam et al. Echocardiographic abnormalities in non-moderate drinking of alcohol for prolonged duration

Although the overall incidence of diastolic dysfunction was $46 \%$, only $35.29 \%$ subjects with DCM had diastolic dysfunction and it was absent when LVEF was less than $35 \%$. MR was the most common among regurgitations.

In a sub analysis, where LV parameters were compared between various groups of subjects ranging from controls to groups with different amount of lifetime intake (Table VI), it was observed that IVS and LVPW thickness had increased and LV diameter had decreased with the amount of alcohol intake. However, this was not evident when the intake amount was more than $500 \mathrm{~kg}$, rather there was thinning of IVS and LVPW and LV dilatation.

Table VI. Mean LV parameters in controls and subjects consuming different lifetime intake amount of alcohol: $(\mathrm{A}-<250 \mathrm{~kg}, \mathrm{~B}-250-500$ $\mathrm{Kg}$ and $\mathrm{C}$ - > $500 \mathrm{Kg}$ ).

\begin{tabular}{l|llll}
\hline Charat. & $\begin{array}{l}\text { Non } \\
\text { alcoholic } \\
(n=50)\end{array}$ & $\begin{array}{l}\text { Group A } \\
(n=7)\end{array}$ & $\begin{array}{l}\text { Group B } \\
(n=22)\end{array}$ & $\begin{array}{l}\text { Group C } \\
(n=21)\end{array}$ \\
\hline LVIDd & 4.32 & 4.59 & 4.41 & 5.37 \\
LVIDs & 2.69 & 3.17 & 3.04 & 4.21 \\
IVSd & 0.9 & 0.94 & 1.02 & 0.92 \\
IVSs & 1.28 & 1.34 & 1.39 & 1.22 \\
LVPWd & 0.85 & 0.91 & 0.97 & 0.93 \\
LVPWs & 1.27 & 1.3 & 1.42 & 1.25 \\
\hline
\end{tabular}

A correlation analysis between total lifetime alcohol consumption amount and LV mass index shows insignificant positive correlation $(r=0.23, p>0.05)$ (Fig.I). Similarly, the relationship between LV mass index and duration of alcohol consumption $(r=0.27$, $\mathrm{p}>0.05)$ and the amount of daily intake $(r=0.16, p>$ 0.05 ) also were not statistically significant. On the other hand, the left ventricular ejection fraction was inversely proportional to the total lifetime of alcohol consumption $(r=-0.91, P<0.001)$ (Fig. II). Although similar relationship between LVEF and the duration of alcohol consumption $(r=0.10, p>0.05)$ was not statistically significant, there was strong inverse relationship with the daily intake amount $(\mathrm{r}=-0.69, \mathrm{p}<0.001)$.

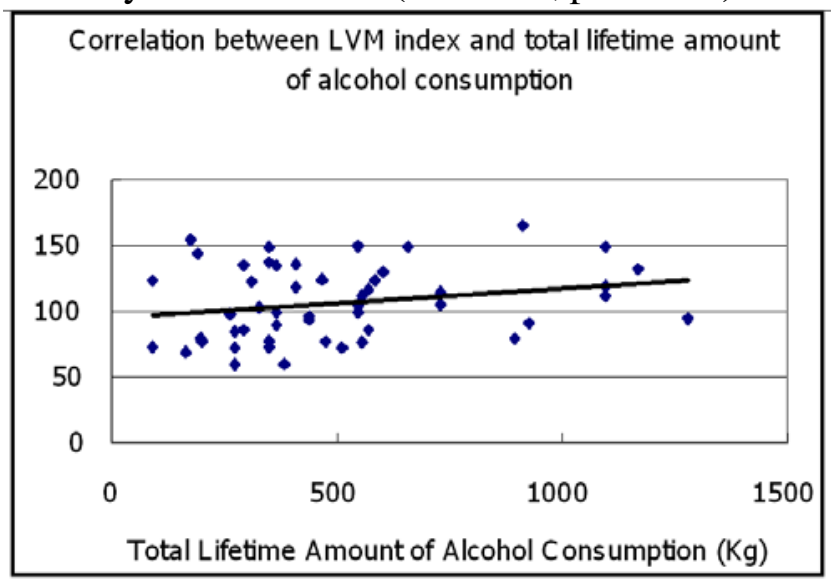

Fig. I: Correlation between total lifetime consumption alcohol amount and LV mass index. $(r=0.23, p>$ $0.05)$

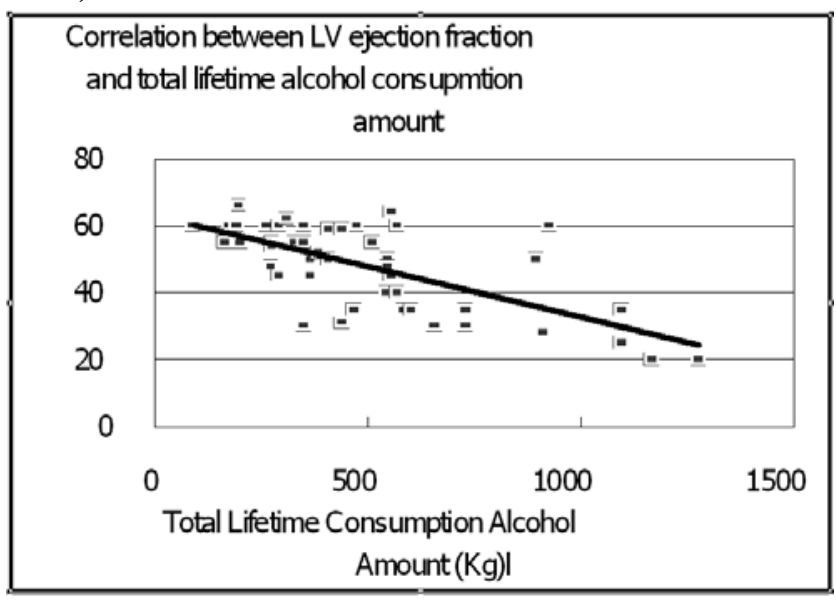

Fig. II: Correlation between LV ejection fraction and total lifetime consumption alcohol amount. $(r=-$ $0.91, \mathrm{p}<0.001)$

\section{Discussion}

This study was focused on echocardiographic assessment of the structural and functional changes caused by prolonged and "at risk drinking" 17 and compared these with that of controls.

In this study, eighty-two percent of subjects 
had abnormal echocardiography. Most common abnormalities were: valvular regurgitation followed by impaired diastolic function, increased LVM, impaired LVEF, and dilated LA and LV in various combinations. Alcohol users had increased thickness of IVS and LVPW. Among regurgitation, isolated MR (24\%) or MR and TR (22\%) were most common. Forty percent of subjects had depressed LVEF and 34\% subjects had echocardiographic features of DCM. Another 10 $\%$ subjects had possible DCM. In overall impaired LVEF was present in $40 \%$, diastolic dysfunction in $46 \%$ and both in $14 \%$ with mean alcohol consumption of $64.3 \mathrm{~g} /$ day for an average duration of 21.9 years and mean lifetime intake amount of $509.97 \mathrm{Kg}$. Similar echo findings were also reported in a case-control study, where the measurement of IVS, LVEF and end diastolic volume was advised for the diagnosis of cardiac damage in alcohol users. ${ }^{27}$

In a study by Urbano-Marquez et al, ${ }^{11}$ where the mean daily alcohol consumption was $243 \mathrm{~g}$ over an average of 16 years, $33 \%$ subjects had developed impaired LVEF $(<55 \%)$. The alcohol users had significant lower mean ejection fraction ( 59 vs $67 \%$ ), greater mean LV end-diastolic diameter (5.1 vs 4.9 $\mathrm{cm}$ ), and greater mean LVM index (123 vs $106 \mathrm{~g} / \mathrm{m}^{2}$ ). In contrast to this, our subjects had taken lesser amount but for longer duration, had higher rate of impaired systolic function, lesser mean LV end-diastolic diameter and lesser LVM index. The differences between these studies are quite explainable if we consider the daily amount of alcohol intake. In the study by UrbanoMarquez al, ${ }^{11}$ the subjects had taken very large amount of alcohol and had developed cardiac abnormalities in younger age. But in our study, subjects had taken lesser amount for longer duration and had developed abnormalities in older age. However, the data on the exact minimal amount and duration to cause alcoholic heart disease could be inaccurate. ${ }^{28}$ Based on observations in the past, it is generally accepted that the consumption of more than $80 \mathrm{~g}$ of alcohol daily (810 units of alcoholic beverage or more than 6-7 standard drinks per day) for at least 10 years, ${ }^{29}$ or total lifetime alcohol consumption $250 \mathrm{Kg}$ is required to cause DCM. ${ }^{30,31}$ Consistent with this observation, none of the subjects in our study with total lifetime alcohol consumption less than $250 \mathrm{Kg}$ had developed abnormal LVEF. However, only $13.64 \%$ of those taking 250-500 $\mathrm{Kg}$ and $76.19 \%$ taking more than $500 \mathrm{Kg}$ had developed LV systolic dysfunction.

Significantly higher rate of echo abnormalities in present study could be due to the presence of symptomatic subjects (32\%) and prolonged ( $\geq 10$ years) duration of non-moderate drinking. It was also observed that despite the large lifetime intake amount and significant echo abnormality compared to controls, majority of subjects had minimal cardiovascular symptoms. Even in alcohol users, there was no correlation of signs and symptoms with the severity of echo abnormality. Only palpitation and dyspnea in combination was significantly associated with impaired LVEF ( $p=0.03$ ) and only the incidence of DCM was higher among symptomatic subjects ( 56.25 vs $23.53 \%$, $\mathrm{p}<0.05)$. It signifies that the cardiovascular symptoms in chronic alcohol user is a feature of advanced myocardial involvement and occurs only after significant reduction in LVEF or overt DCM has already occurred. Similar incidence of echocardiographic features of impaired LVEF in asymptomatic alcohol users was also reported by Urbano-Marquez et al (33\%). ${ }^{11}$

McKenna et al ${ }^{26}$ conducted a case control study in a well-characterized cohort of DCM and randomly 
MP Gautam et al. Echocardiographic abnormalities in non-moderate drinking of alcohol for prolonged duration

selected population based control group. They showed that the prolonged excess alcohol consumption was a possible etiologic agent in at least $40 \%$ cases. The alcohol consumption among subjects with DCM was significantly higher in comparison to control exceeding weekly limit (by $40 \%$ vs $24 \%$, p $<0.01$ ). Average total lifetime consumption was $31200 \mathrm{U}$ i.e. $249.6 \mathrm{Kg}$ in cases and 7904 U i.e. $63.23 \mathrm{Kg}$ in control ( $<<0.01)$. Surprisingly our subjects had consumed larger lifetime amount, far exceeding the amount reported in this study but the incidence of echocardiographic abnormalities (82\%) including impaired LVEF (40\%) and increased LV mass (44\%) were similar to those and the echo changes were uncommon in subjects taking less than $250 \mathrm{Kg}$ of ethanol in lifetime. This may indicate that a high daily intake over short duration is more harmful than smaller amount over long period despite similar lifetime amount.

Another study, which had assessed the echocardiographic abnormalities in chronic asymptomatic alcohol users, showed that the asymptomatic alcohol users had LV dilatation with preserved LVEF and impaired LV relaxation. In alcohol users there was higher LVM index (92 vs 78 $\left.\mathrm{g} / \mathrm{m}^{2}, \mathrm{p}<0.001\right)$ and thicker LVPW (0.9 vs $0.8 \mathrm{~cm}$, $\mathrm{p}<0.001)$. Multiple regression analysis identified duration of heavy alcohol consumption as the most important variable affecting diastolic function. ${ }^{32}$ Present study also shows similar increase in LVM, LVM index and LVPW thickness but we were unable to demonstrate any positive relation between LV relaxation abnormalities and duration because higher proportion of our subjects had significant systolic dysfunction which had probably pseudonormalized the diastolic dysfunction. Our study also showed that in alcohol users initially there is thickening of IVS and
LVPW with preserved systolic function and impaired diastolic relaxation in association with decrease in LV dimension. Then on further continuation of drinking, LV systolic function will start to deteriorate due to LV dilatation in association with pseudonormalization of diastolic dysfunction and thinning of IVS and LVPW. In other words, there is U shaped relationship between lifetime amount and LV dimensions and inverted $\mathrm{U}$ shaped relationship with IVS and LVPW thickness. In consistent to our study, Kajander et al ${ }^{32}$ had also demonstrated similar $\mathrm{U}$ shaped relation of $\mathrm{LV}$ size with increasing daily alcohol use.

Fernandez - Sola et $\mathrm{al}^{33}$ conducted a study in which thirty-five alcoholics with cardiomyopathy (ejection fraction < 50\%) and 77 healthy alcohol users (ejection fraction $>50 \%$ ) were evaluated for diastolic function with two-dimensional doppler echocardiography. It showed that the diastolic dysfunction was present in $33 \%$ alcohol users without cardiomyopathy, compared with $66 \%$ subjects with cardiomyopathy $(\mathrm{p}<0.01)$. A pseudonormalization phenomenon of diastolic function was observed in patients with more advanced systolic dysfunction (LVEF $<32 \%)$. The deterioration of the diastolic parameters correlated with ethanol consumption. Our study also showed higher incidence of diastolic dysfunction in alcohol users. However, the incidence of diastolic dysfunction, though statistically not significant, was more common in subjects with normal LVEF (53.33 vs 35\%, p > 0.05). Only $35.29 \%$ subjects with DCM had diastolic dysfunction and it was absent when LVEF was less than $35 \%$ supporting the concept of pseudonormalization of diastolic function. Other studies were unable to demonstrate the presence of systolic dysfunction in alcohol users and the common 
echocardiographic findings were the presence of diastolic dysfunction, thickening of IVS and LVPW. ${ }^{34,35}$

Regarding LVM, similar higher incidence of raised LVM was also observed in Framingham study ${ }^{36}$ where alcohol intake was positively associated with LVM in men $(\mathrm{p}<0.05)$ but not in women $(\mathrm{p}>0.05)$ and in a study by Kupari et al, ${ }^{37}$ where the LVM index and the LVPW thickness were significantly higher in alcohol users (85 vs $77 \mathrm{~g} / \mathrm{m}^{2}, \mathrm{p}<0.001$ and $1.1 \mathrm{vs}$ $1.0 \mathrm{~cm}, \mathrm{p}<0.05$ respectively).

In a correlation analysis, although the LVM index was directly proportional to the total lifetime amount $(\mathrm{r}=0.23, \mathrm{p}>0.05)$, duration $(\mathrm{r}=0.27, \mathrm{p}>0.05)$ and daily amount $(\mathrm{r}=0.16, \mathrm{p}>0.05)$, none of these relations were statistically significant. So our study does not support the idea of linear increase in LVM index with the duration and daily amount as shown in few other studies. However systolic dysfunction was strongly proportional to the total lifetime of alcohol amount $(r=-0.91, p<0.001)$. But, when analyzed separately this relationship was true only in the case of daily amount $(r=-0.69, p<0.001)$, not in the case of duration $(r=0.1, p>0.05)$. Similar correlation was recorded in a study by Urbano-Marquez et al ${ }^{11}$, which showed that the estimated total lifetime amount of alcohol consumption was inversely correlated with the $\operatorname{LVEF}(\mathrm{r}=-0.58, \mathrm{p}<0.001)$. In contrast to our study, this showed proportional relationship between lifetime intake amount and the $\operatorname{LVM}(r=0.59, \mathrm{p}<0.001)$. Some other studies also showed similar linear relation of LVEF and LVM index ${ }^{11}$ other showed either non-linear ${ }^{33}$ or failed to find any relation ${ }^{37,38,39}$ with the total lifetime intake of alcohol.

\section{Conclusion}

Our study reinforces that non-moderate drinking for a long duration is a risk factor for cardiovascular health causing significant structural and functional changes even without causing any symptoms in victims till late stage. The most common and early echocardiographic abnormality is diastolic dysfunction. On further continuation of drinking habit, the systolic function starts to deteriorate causing pseudonormalization of diastolic function. Other echo abnormalities include higher LVM, dilated LA and LV and regurgitation. The echocardiographic changes in non-moderate drinking are variable with variable relation to amount and duration. Our study showed strong negative correlation of the LVEF with the lifetime intake and daily amount of alcohol consumption. Similarly, the total lifetime intake amount has an inverted U type relationship with IVS and LVPW and shallow U shape relationship with LV diameter. The alcohol users remain asymptmatic till late stage in spite of echocardiographically detected structural and functional changes and once they became symptomatic the disease may be in advanced stage and abstinence may not stop or reverse the changes.

Echocardiography could be an important tool for the screening of alcoholic heart disease including DCM in preclinical stage when it is asymptomatic and the effect of alcohol on myocardium may be reversible. Unexplained LV hypertrophy, diastolic dysfunction or impaired systolic function should raise the suspicion of alcohol abuse. So it seems prudent to advise patients with such features to abstain alcohol and for those who want to enjoy alcoholic beverages and have not suffered from any illness, consumption should be restricted to safe limit. 
MP Gautam et al. Echocardiographic abnormalities in non-moderate drinking of alcohol for prolonged duration

Acknowledgement

I wish to express my gratitude to Dr VP Sharma, Dr SK Sharma, Dr JAAnsari and Dr P. Karki for the support and encouragement.

\section{References}

1. Schuckit SA. Alcohol and Alcoholism. In: Braunwald E, Fauci AS, Kasper DL, Hauser SL, Longo DL, Jameson JL, editors. Harrison's Principle of Internal Medicine. $15^{\text {th }}$ edition, New York: Mc-Graw Hill; 2001. 2561-6.

2. Doll $R$, Peto $R$, Hall E et al. Mortality in relation to consumption of alcohol: 13 years' observations on male British doctors. BMJ 1994;309:911-8.

3. Marmot M, Brunner E. Alcohol and cardiovascular disease: the status of the $U$ shaped curve. BMJ 1991;303:565-8.

4. Shaper AG, Wannamethee SG. Alcohol intake and moratlity in middle-aged men with diagnosed coronary heart disease. Heart 2000;83:394-6.

5. Albert CM, Manson JE, Cook NR, et al. Moderate Alcohol Consumption and the Risk of Sudden Cardiac Death Among US Male Physicians. Circulation 1999;100:944-50.

6. Rimm EB, Klatsky A, Grobbee D et al. Review of moderate alcohol consumption and reduced risk of coronary heart disease: is the effect due to beer, wine, or spirits? BMJ 1996;312:731-6.

7. McElduff P, Dobson AJ. How much alcohol and how often? Population based case-control study of alcohol consumption and risk of a major coronary event. BMJ 1997;314:1159-64.

8. Sesso HD, Stampfer MJ, Rosner B, et al. Seven-year changes in alcohol consumption and subsequent risk of cardiovascular disease in men. Arch Intern Med 2000;160:2605-12.
9. Friedman LA, Kimball AW. Coronary heart disease mortality and alcohol consumption in Framingham. Am J Epidemiol 1986;124:481-9.

10. Rimm EB, Giovannucci EL, Willett WC, et al. Prospective study of alcohol consumption and risk of coronary disease in men. Lancet 1991;338:464-8.

11. Urbano-Marquez, A, Estruch R, Navarro-Lopez F, et al. The effects of alcoholism on skeletal and cardiac muscles. N Eng J Med 1989;320:409-15.

12. Matthews EC, Gardin JM, Henry WL, et al. Echocardiographic abnormalities in chronic alcoholics with and without heart failure. Am J Cardiol 1981;47:570-8.

13. Fauchier L, Babuty D, Poret P. Comparision of longterm outcome of alcoholic and idiopathic cardiomyopathy. Eur Heart J 2000;21:306-14.

14. Pavan D, Nicolosi CL, Lestuzzi C, et al. Normalization of variables of left ventricular function in patients with alcoholic cardiomyopathy after cessation of excessive alcohol intake: an echocardiographic study. Eur Heart J 1987;8:535-40.

15. Agatston AS, Snow ME, Samet P. Regression of severe alcoholic cardiomyopathy after abstinence of 10 weeks. Alcoholism 1986;10:386-7.

16. Takehana H, Izumi T. Alcoholic heart disease. Nippon Rinsho 2000;58:151-6.

17. Fiellin DA, Reid MC, O'Connor PG. Screening for alcohol problems in primary care: systematic review. Arch Intern Med 2000;160:1977-89.

18. Criqui MH. Moderate drinking; benefits and risks. In: Zakhari S, Wassef M, eds. Alcohol and the Cardiovascular System, Research Monograph 31. Bethesda: National Institute of Alcohol Abuse and Alcoholism, US Department of Health and Human Services 1996. 117-23.

19. Sobell LC, Maisto SA, Sobell MB, et al. Reliability of alcohol abusers' self-reports of drinking behavior. Behav Res Ther 1979;17:157-60.Editorials. Alcohol intake: measure for measure. BMJ 2001; 323:143940 . 
20. Sahn DJ, DeMaria A, Kisslo J, et al for the Committee on M-mode Standardization of the American Society of Echocardiography. Recommendations regarding quantitation in M-mode echocardiography: results of a survey of echocardiographic methods. Circulation 1978;58:1072-83..

21. Devereux RB, Alonso DR, Lutas EM, et al. Echocardiographic assessment of left ventricular hypertrophy: comparison with necropsy findings. Am J Cardiol 1986;57:450-8.

22. Gardin JM, Siscovick D, Anton-Culver H, et al. Sex, Age, and Disease Affect Echocardiographic Left Ventricular Mass and Systolic Function in the FreeLiving Elderly. The Cardiovascular Health Study. Circulation 1995; 91:1739-48.

23. Henry WL, DeMaria A, Feigenbaum H, et al. Report of the American Society of Echocardiography Committee on Nomenclature and Standards: Identification of Myocardial Wall Segments. Raleigh, NC: American Society of Echocardiography; 1982.

24. Feigenbaum H. Echocardiographic evaluation of cardiac chambers. In: Feigenbaum $H$ ed. Echocardiography Fifth edition. USA: Lea \& Febiger. 1993.134-80.

25. Elliott PM. Cardiomyopathy, Diagnosis and management of dilated cardiomyopathy. Heart 2000;84:106-12.

26. McKenna CJ, Codd MB, McCann HA, et al. Alcohol consumption and idiopathic dilated cardiomyopathy: a case control study. Am Heart J 1998;135:833-7.

27. Scafa $F$, Mingrone $R$, Perottin $N$, et al. Echocardiographic assesment of alcohol consumers in different clinical stages. Minnerva Med 1996;87:407-11.

28. Balk AHMM. Editorial, Dilated cardiomyopathy: are a few drinks allowed? European Heart Journal 2000;21:267-9.

29. Duer AR, Stamler J, Paul O, et al. Alcohol consumption, cardiovascular risk factors and mortality in two
Chicago epidemiologic studies. Circulation 1977;56:1067-74.

30. Richardson PJ, Wodak AD, Arkinson, et al. Relation between alcohol intake, myocardial enzyme activity and myocardial function in dilated cardiomyopathy. Evidence for the concept of alcohol induced heart muscle disease. Br Heart J 1986;56:165-70.

31. Lazarevia AM, Nakatani S, Neskovia AN, et al. Early changes in left ventricular function in chronic asymptomatic alcoholics: relation to the duration of heavy drinking. J Am Coll Cardiol 2000; 35: 1599 606.

32. Kajander OA, Kupari M, Laippala P, et al. Dose dependent but non-linear effects of alcohol on the left and right ventricle. Heart 2001;86:417-23.

33. Fernandez-Sola J, Nicolas JM, Pare JC, et al. Diastolic function impairment in alcoholics. Alcohol Clin Exp Res 2000 ;24:1830-5.

34. Wehr M, Hess J, Noll B, et al. Cardiac findings in alcoholic liver diseases. Med Klin 1990;85:629-36.

35. Maiorano G, Bartolomucci F, Contursi V, et al. Noninvasive detection of vascular dysfunction in alcoholic patients. Am J Hypertens 1999;12:137-44.

36. Manolio TA, Levy D, Garrison RJ, Castelli WP, et al. Relation of alcohol intake to left ventricular mass: the Framingham Heart Study. J Am Coll Cardiol 1991;17:717-21.

37. Kupari M, Koskinen P, Suokas A. Left ventricular size, mass and function in relation to the duration and quantity of heavy drinking in alcoholics. Am J Cardiol 1991;67:274-9.

38. Askanas A, Udoshi M, Sadjadi SA. The heart in chronic alcoholism: a non-invasive study. Am Heart J 1980;99:9-16.

39. Kino M, Imamitchi $H$, Morigutchi $M$, et al. Cardiovascular status in asymptomatic alcoholics, with reference to the level of ethanol consumption. $\mathrm{Br}$ Heart J 1981;46:545-51. 